\title{
Formaldehyde and peroxide concentrations in Law Dome (Antarctica) firn and ice cores
}

\author{
R.W. Gillett, ${ }^{1}$ T. D. van Ommen, ${ }^{2}$ A.V. Jagkson, ${ }^{3}$ G. P. Ayers ${ }^{1}$ \\ ${ }^{1}$ Commonwealth Scientific and Industrial Research Organisation, Atmospheric Research, Aspendale, Victoria 3195, Australia \\ ${ }^{2}$ Antarctic CRC and Australian Antarctic Division, Box 252-80, Hobart, Tasmania 7001, Australia \\ ${ }^{3}$ The Environment Centre, University of Leeds, Leeds LS2 97T, England
}

\begin{abstract}
Peroxide speciation and formaldehyde measurements have been made on ice cores retrieved from Law Dome, Antarctica. Measurements were made for ice deposited during four different periods: modern, pre-industrial Holocene, early Holocene and Last Glacial Maximum (LGM). The data show modern peroxide levels $>50 \%$ above pre-industrial levels $\left(\right.$ at $\left.\sim 1.6 \mu \mathrm{mol} \mathrm{L}^{-1}\right)$ and an absence of methyl hydroperoxide (down to a detection threshold of $0.003 \mu \mathrm{mol} \mathrm{L}{ }^{-1}$ ). Formaldehyde levels show a $40 \%$ increase from pre-industrial to modern times (rising from $\sim 0.07 \mu \mathrm{mol} \mathrm{L}^{-1}$ to $\sim 0.10 \mu \mathrm{mol} \mathrm{L}^{-1}$ ), with a further increase and possible seasonality near the surface which we associate with post-depositional processes. Peroxide levels in LGM ice are low, but formaldehyde concentrations are high $\left(\right.$ at $\left.\sim 0.13 \mu \mathrm{mol} \mathrm{L}^{-1}\right)$ relative to modern levels. Similar high levels of formaldehyde are seen in early Holocene ice $(\sim 6900$ years BP).
\end{abstract}

\section{INTRODUGTION}

Ice cores provide a valuable and productive means of studying past changes in climatic conditions. Concentrations of gases such as $\mathrm{CO}_{2}, \mathrm{CH}_{4}$ and $\mathrm{CO}$ and isotopes of oxygen have been measured in ice cores from Greenland and Antarctica in order to deduce information about past atmospheric chemistry and its connection with major climatic shifts such as ice ages (Barnola and others, 1987, 1995; Chappellaz and others, 1990; Etheridge and others, 1996). Concentrations of dissolved species also provide valuable indicators for past atmospheric chemistry. Among the numerous species detected in polar ice, $\mathrm{H}_{2} \mathrm{O}_{2}$ and $\mathrm{HCHO}$, which are oxidation products of $\mathrm{CO}$ and $\mathrm{CH}_{4}$, are important constituents (Sigg and Neftel, 1991; Staffelbach and others, 1991; Fuhrer and others, 1993; Jacob and Klockow, 1993; Neftel and others, 1995; Van Ommen and Morgan, 1996). Since $\mathrm{CH}_{4}$ and $\mathrm{CO}$ in the gas phase are oxidised almost exclusively by the $\mathrm{OH}$ radical, knowledge of the levels of their oxidation products in ice cores may permit assessment of past changes in $\mathrm{OH}$ concentration and consequently in the oxidising ability of the atmosphere (Thompson, 1995). However, deconvolution of ice-core records of species such as hydrogen peroxide and formaldehdye in order to study past changes in atmospheric chemistry is complicated by other factors, such as postdepositional processes, that may modify the atmospheric signal. Thus, in addition to high-quality ice-core data, a fundamental understanding of air-ice transfer processes and post-depositional change is required in order to infer past atmospheric chemical conditions.

The aim of this paper is to address the first of these requirements, which is the establishment of a high-quality icecore data record, in our case from Law Dome, East Antarc- tica. The second requirement, interpretation of the data record in terms of past atmospheric processes, will be addressed in due course after additional work on air-ice exchange at Law Dome, and validation of an atmospheric photochemical model for this site.

This work reports measurements of $\mathrm{H}_{2} \mathrm{O}_{2}$, methyl hydroperoxide $\left(\mathrm{CH}_{3} \mathrm{OOH}\right)$ and $\mathrm{HCHO}$ made in ice-core samples from Law Dome, Antarctica. Although $\mathrm{CH}_{3} \mathrm{OOH}$ has not been detected in studies elsewhere, measurements were made on Law Dome samples because the detection technique used was more sensitive than before, and the organic peroxide is expected to be considerably more important in Antarctic than in Arctic air (due to a much higher atmospheric $\mathrm{CH}_{4} / \mathrm{CO}$ ratio in the Southern than in the Northern Hemisphere).

Measurements were made in samples from the modern and pre-industrial periods and the Last Glacial Maximum (LGM). The HCHO measurements reported here are the first such analyses for any Law Dome core, and the $\mathrm{CH}_{3} \mathrm{OOH}$ analysis constitutes the most sensitive search for this species in polar ice/snow yet reported in the literature. The new ice-core data presented here were obtained from the Dome Summit South (DSS) ice core, drilled on Law Dome. This core provides a very high-resolution record which extends back beyond the last glacial and has clearly preserved seasonal cycles in hydrogen peroxide (Van Ommen and Morgan, 1996) that have been detected at ages of several thousand years. The site has a high accumulation rate $(0.7 \mathrm{~m}$ ice $\mathrm{a}^{-1}$ ) and a relatively low mean wind speed (Morgan and others, 1997) for East Antarctica. These properties lead to rapid burial and minimisation of wind-induced ventilation of the near-surface snow. Such conditions are thought favourable (Waddington and others, 1996) for preservation in the ice of such reversibly deposited species as $\mathrm{H}_{2} \mathrm{O}_{2}$ and 
$\mathrm{HCHO}$ at, or close to, the concentrations at the time of deposition. The DSS material used for the pre-industrial and LGM periods was augmented, for the modern period, with material from a fresh shallow core (denoted as DSS96P) retrieved from the site in February 1996. To minimise the risk of drilling in a previously disturbed site, DSS96P was drilled $840 \mathrm{~m}$ from the DSS borehole at a bearing of $208^{\circ}$, which is approximately on the same accumulation isopleth.

\section{EXPERIMENTAL METHODS}

The ice was sampled at four deposition periods corresponding to ages (before present: 1996.0) of 0-15, 330-450, 6900 and 13700 years. The core dating was achieved by direct counting of annual layers down to AD 1300, below which an ice-flow model constrained by spot layer-thickness measurements was used (Van Ommen and Morgan, 1996; Morgan and others, 1997). We believe that this model (which assumes a simple flow law) generates ages which are systematically too young beyond about several thousand years, probably as a result of unmodelled stagnant ice near the base of the sheet. The LGM at this site is defined as the coldest stage of the last glaciation as estimated from isotope measurements. The samples used in this study are dated at around $13700 \mathrm{BP}$, when the temperature was estimated to be about $15.9^{\circ} \mathrm{C}$ colder than now (Van Ommen and Morgan, 1997).

For all epochs, ice was cut in discrete samples that were melted immediately prior to analysis. The sampling in the modern and pre-industrial sections was arranged to provide a resolution of 0.1 year, while the samples from older sections represented averages over many years to decades. As noted in the introduction, the core material used for the modern epoch was retrieved in February 1996, just 1 month before analysis. This rapid analysis was undertaken to minimise concerns about possible post-drilling changes in peroxide levels. Two parallel sets of samples were prepared from identical depths to provide independent samples for the subsequent analyses. One of the sets was analyzed for total peroxides. The other was divided, upon melting, into two aliquots. One aliquot was analyzed for $\mathrm{HCHO}$ and the other was used for the measurement of individual peroxides.

Total peroxide measurements were made with a commercial diffraction-grating fluorimeter (GBC 1250 Fluoro detector) using the enzymatic fluorimetric analysis method (Lazrus and others, 1985; Sigg and Neftel, 1988) as discussed in an earlier paper (Van Ommen and Morgan, 1996). The detection limit was approximately $0.015 \mu \mathrm{mol} \mathrm{L}^{-1}$, with a $1 \sigma$ deviation for single measurements in the range 0.030 $0.06 \mu \mathrm{mol} \mathrm{L}{ }^{-1}$, based on response of calibration standards.

Formaldehyde concentrations were measured using the fast-flow injection analysis of Dong and Dasgupta (1987). This technique relies upon the Hantzsch reaction which produces a derivative, 3,5-diacetyl-1,4-dihydrotolutidine, from the cyclisation reaction of formaldehyde with $\mathrm{NH}_{3}$ (ammonium acetate) and 2,4-pentanedione. Immediately after the ice samples were melted, an aliquot was injected into the system via a six-port Rheodyne 7125 injector with a loop having a volume of approximately $800 \mu \mathrm{L}$. High-purity water, used as the mobile phase, was pumped through the system with a peristaltic pump so that the ice-core sample was injected into the water stream; the 2,4-pentanedione/ammonium acetate reagent was added to the liquid line downstream of the injector. The liquid was heated to $95^{\circ} \mathrm{C}$ in an in-line heating block to ensure the reaction was complete, and then passed through a small length of GoreTex TA-001 hydrophobic membrane tubing to remove air bubbles introduced by the heating. The concentration of the derivative in the liquid was measured with a fluorescence detector (GBC LC 1250 Fluoro Detector) at an excitation wavelength of $412 \mathrm{~nm}$ and an emission wavelength of $510 \mathrm{~nm}$. Concentrations of HCHO were calculated using standard formaldehyde solutions which were serially diluted daily from a standardised formaldehyde solution. Peak heights of the standards were found to be linear over a concentration range of $<0.03$ to $>6 \mu \mathrm{mol} \mathrm{L}^{-1}$.

Samples were analyzed for individual peroxides using high-pressure liquid chromatography (HPLC), allowing the separation and quantification of $\mathrm{H}_{2} \mathrm{O}_{2}$ and individual organic hydroperoxides. Detection was based on the horseradish peroxidase (Sigma-Aldrich, type II) enzyme-catalysed dimerisation of p-hydroxyphenylacetic acid (Lazrus and others, 1986).

Samples were injected via a Rheodyne 9125 metal free injector valve onto a $100 \mu \mathrm{L}$ sample loop from a sample volume of $250 \mu \mathrm{L}$. To reduce particulate contamination, samples were passed through $0.2 \mu \mathrm{m}$ ion-chromatography syringe filters (Anachem) prior to injection. Separation was achieved using a $5 \mu \mathrm{m}$ Alltech Adsorbosphere $(4.6 \times 250 \mathrm{~mm})$ MF-Plus C18 column, with an eluent of $1 \mathrm{mmol} \mathrm{L}^{-1} \mathrm{H}_{2} \mathrm{SO}_{4}$ and $100 \mu \mathrm{mol} \mathrm{L}$ ethylenediaminetetra-acetic acid in Milli-Q water. Eluent was delivered by a Merck-Hitachi L-6200 Intelligent pump at a flow rate of $0.6 \mathrm{~mL} \mathrm{~min}{ }^{-1}$.

Separated compounds were then derivatised by the addition of $26 \mathrm{mmol} \mathrm{L}^{-1}$ p-hydroxyphenylacetic acid with $10^{5}$ units $\mathrm{L}^{-1}$ of horseradish peroxidase, in potassium hydrogen phthalate buffer, at $\mathrm{pH} 5.8$ delivered by a Gilson peristaltic pump ( $0.25 \mathrm{~mm}$ inside-diameter tubing). After reaction in a Teflon mixing coil, derivatised peroxides were passed through a Nafion membrane reactor (Omnifit, England), immersed in $150 \mathrm{~mL}$ of $30 \% \mathrm{NH}_{4} \mathrm{OH}$ which raised the $\mathrm{pH}$ above 10 , to convert the dimer to an anionic form, maximising fluorescence for detection. A Merck-Hitachi detector was used, at excitation and emission wavelengths of 310 and $405 \mathrm{~nm}$, respectively.

Peroxide peak identities were confirmed by comparison with retention times of authentic standards. Commercially available $30 \% \quad \mathrm{H}_{2} \mathrm{O}_{2}$ and $36-40 \mathrm{wt} \%$ peroxyacetic acid (Sigma-Aldrich) were used, whilst methyl hydroperoxide ethyl hydroperoxide, hydroxymethyl hydroperoxide, 2-hydroxyethyl hydroperoxide and 2-hydroxypropyl hydroperoxide were synthesised using modified methods of Reiche and Meister (1933, 1935) and Davies and Deary (1992).

All hydroperoxides react to form the same fluorescent dimer, producing an equivalent molar response. Therefore, HPLC calibration was performed using $\mathrm{H}_{2} \mathrm{O}_{2}$ only, with calibration standards made daily by the serial dilution of commercially available $30 \% \mathrm{H}_{2} \mathrm{O}_{2}$ (Sigma-Aldrich) with Milli-Q water. Calibration was found to be linear over the range $1 \mathrm{nmol} \mathrm{L}{ }^{-1}$ to $10 \mu \mathrm{mol} \mathrm{L}^{-1}$.

The limit of detection and limit of quantification for the HPLC have been taken as three times and ten times the standard deviation at zero analyte, respectively, at 95\% confidence, as defined by Heavner and others (1992). This leads to calculated values of 3 and $11 \mathrm{nmol} \mathrm{L}^{-1}$, respectively. Precision was found to be $1 \%$ for repeat injections of a $1.7 \mu \mathrm{mol} \mathrm{L}{ }^{-1} \mathrm{H}_{2} \mathrm{O}_{2}$ standard solution. 


\section{RESULTS AND DISCUSSION}

The individual peroxides analysis failed to show any $\mathrm{CH}_{3} \mathrm{OOH}$ or other organic peroxides in the ice from any of the epochs, even in the relatively fresh (1 month old) firn samples. This confirms at Law Dome the work of others (Sigg and Neftel, 1988, 1991; Jacob and Klockow, 1993) who have reported an absence of organic peroxides in ice cores from Greenland and Antarctica. The notable difference is that our HPLC method places a new upper limit of approximately $0.003 \mu \mathrm{mol} \mathrm{L}^{-1}$ on the ice-core $\mathrm{CH}_{3} \mathrm{OOH}$ level, compared with prior results which reported lower sensitivities of $\sim 0.015 \mu \mathrm{mol} \mathrm{L}^{-1}$.

The parallel measurements of $\mathrm{H}_{2} \mathrm{O}_{2}$ with the HPLC system and of "total peroxides" with the standard flow-injection system showed extraordinary agreement (Fig. 1), confirming that "total peroxides" equals $\mathrm{H}_{2} \mathrm{O}_{2}$ and that the ice is essentially devoid of organic peroxides. The remarkable agreement between the independent analytical methods is evident from the mean difference from 120 measurements of only $15 \pm 9 \mathrm{nmol} \mathrm{L}^{-1}$, on an average absolute level of $>1.5 \mu \mathrm{mol} \mathrm{L}^{-1}$. The corresponding $1 \sigma$ variation in measurement difference between single measurements using the two techniques is $110 \mathrm{nmol} \mathrm{L}^{-1}$. Although this is larger than the error quoted in the previous section for calibration standard measurements, it includes a contribution due to the variability between separate samples prepared in parallel. Minor differences in sample handling, cut geometry and local porosity variations in the firn can all be expected to lead to small discrepancies in parallel samples from the same piece of core.

The results of the analysis are summarised in Tables 1 and 2. The modern epoch consists of 13 separate years in three separate periods, "modern-a" (1993.0-1996.0), "modern-b" (1986.0-1992.0) and "modern-c" (1981.5-1985.5). The modern-b data come from earlier analysis for $\mathrm{H}_{2} \mathrm{O}_{2}$ only (Van Ommen and Morgan, 1996) and are presented here to provide improved statistics for this period. In similar fashion, the pre-industrial $\mathrm{HCHO}$ and individual $\mathrm{ROOH}$ measurements (pre-industrial-b) have been augmented with a mean (pre-industrial-a) from a longer series of earlier $\mathrm{H}_{2} \mathrm{O}_{2}$ measurements (Van Ommen and Morgan, 1996). The data are plotted in Figure 2.

The data were reduced to averages over a whole number of years to avoid biases (which would arise for peroxide, at least, as a result of the strong seasonality). Both $\mathrm{H}_{2} \mathrm{O}_{2}$ and $\mathrm{HCHO}$ series display large interannual variability, no doubt due to the stochastic nature of precipitation events and the effect of this on snow retention, as well as fluctuations in tropospheric gas-phase concentrations. In the case of $\mathrm{H}_{2} \mathrm{O}_{2}$ these interannual differences are known to show a $1 \sigma$ variability (Van

Table 1. Sampling parameters

\begin{tabular}{lccc} 
Epoch & Mean age $^{\mathrm{a}}$ & Tears sampled & Samplesmeasured \\
\hline Modern-a & 1.5 & 3 & 33 \\
Modern-b & 7.5 & 6 & 144 \\
Modern-c & 12.5 & 4 & 47 \\
Pre-industrial-a & 348 & 38 & 209 \\
Pre-industrial-b & 455 & 3 & 33 \\
Early Holocene & 6900 & $\sim 50$ & 10 \\
LGM & 13700 & $\sim 700$ & 10 \\
& & & \\
\hline
\end{tabular}

${ }^{\text {a }}$ Years before 1996.0.
Table 2. Summary of results

\begin{tabular}{lcccc} 
Epoch & \multicolumn{2}{c}{$\mathrm{H}_{2} \mathrm{O}_{2}$} & \multicolumn{2}{c}{$\mathrm{HCHO}$} \\
& Mean $^{\mathrm{a}}$ & Range $^{\mathrm{b}}$ & Mean $^{\mathrm{a}}$ & Range $^{\mathrm{b}}$ \\
& $\mu \mathrm{mol} \mathrm{L}^{-1}$ & $\mu \mathrm{mol} \mathrm{L}^{-1}$ & $\mu \mathrm{mol} \mathrm{L}^{-1}$ & $\mu \mathrm{mol} \mathrm{L}^{-1}$ \\
\hline Modern-a & $2.1 \pm 0.4$ & $0.35-3.88$ & $0.22 \pm 0.03$ & $0.093-0.478$ \\
Modern-b & $1.7 \pm 0.2$ & $0.12-4.52$ & & \\
Modern-c & $1.6 \pm 0.2$ & $0.26-3.76$ & $0.10 \pm 0.01$ & $0.066-0.184$ \\
Pre-industrial-a & $1.0 \pm 0.06$ & $0.14-3.49$ & & \\
Pre-industrial-b & $1.2 \pm 0.2$ & $0.12-2.38$ & $0.07 \pm 0.01$ & $0.046-0.224$ \\
Early Holocene $^{\mathrm{c}}$ & $0.6 \pm 0.06$ & $0.35-1.12$ & $0.13 \pm 0.003$ & $0.113-0.168$ \\
Early Holocene $^{\mathrm{c}}$ & & & $0.13 \pm 0.01$ & $0.102-0.204$ \\
Early Holocene $^{\mathrm{d}}$ & & & $0.16 \pm 0.01$ & $0.099-0.243$ \\
LGM & $0.2 \pm 0.03$ & $0.09-0.35$ & $0.14 \pm 0.001$ & $0.082-0.199$
\end{tabular}

\footnotetext{
${ }^{\text {a }}$ Mean and standard deviation are computed for annual average values.

${ }^{\mathrm{b}}$ Range is computed for individual samples and includes sub-annual variation where sampling is sufficiently fine.

${ }^{\mathrm{c}}$ DSS1141 repeat.

${ }^{\mathrm{d}}$ DSS1140, adjacent core.
}

Ommen and Morgan, 1996) on the order of 30\% for annual averages (computed from peroxide analysis results from the DSS core for a 262 year period, AD 1580-1842). This figure of $30 \%$ variability (scaled by the square root of the number of years averaged) was used to estimate the standard error in the modern and pre-industrial mean values plotted in Figure 2. Standard errors quoted for the early Holocene and LGM measurements are calculated directly as $\sigma / \sqrt{N}$ for the $N$ measurements in each period. For the HCHO means, these

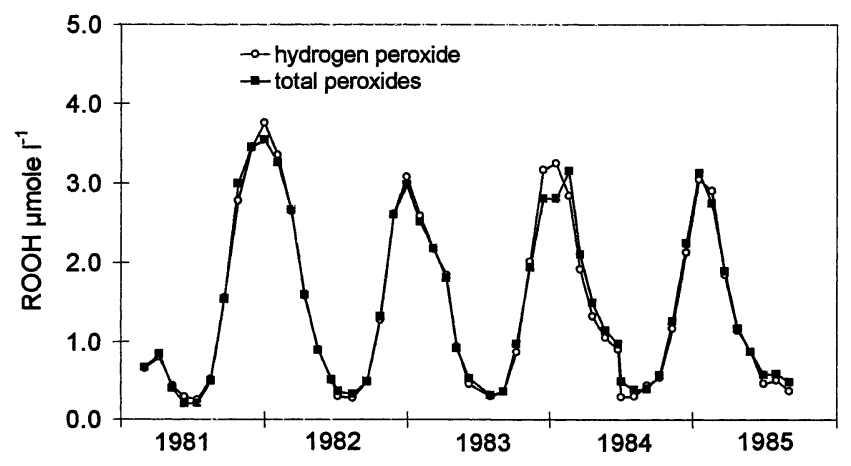

Fig. 1. Comparison of total peroxides and hydrogen peroxide concentrations in ice cores, 1980-85.

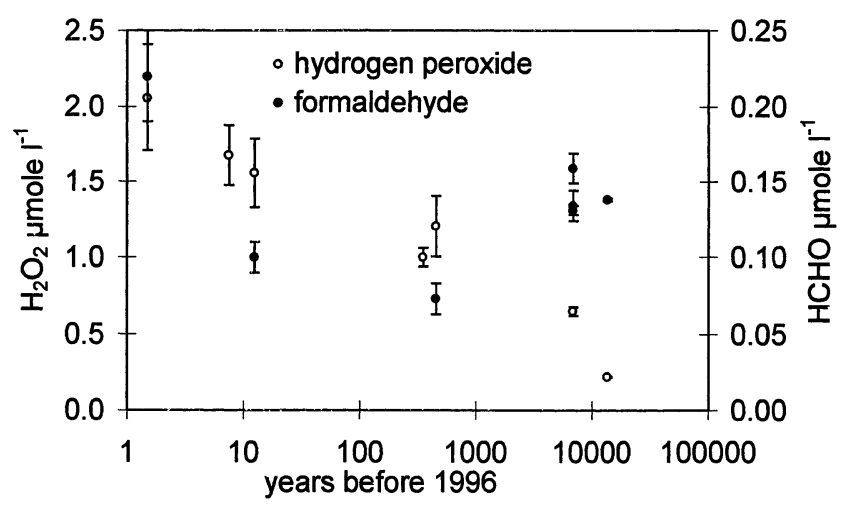

Fig. 2. Mean $\mathrm{H}_{2} \mathrm{O}_{2}$ and $\mathrm{HCHO}$ concentrations with age. Error bars are one standard deviation amplitude, computed from estimated interannual variability as described in the text. 
are the first results available on the DSS core, and the best estimate we have for the variability comes from the annual values measured here. We have taken $20 \%$ as a representative figure for the $1 \sigma$ annual variation in $\mathrm{HCHO}$, and computed standard errors for the $\mathrm{HCHO}$ means as for the $\mathrm{H}_{2} \mathrm{O}_{2}$ means. This lower interannual variability for $\mathrm{HCHO}$ than for $\mathrm{H}_{2} \mathrm{O}_{2}$ is consistent with the much higher diffusion smoothing exhibited by HCHO.

The peroxide measurements agree well with earlier measurements detailed in Van Ommen and Morgan (1996), although the modern series presented here was analyzed under more controlled conditions than the previously published modern data and is of higher quality. Of particular note is the fact that the summer peroxide peak of 1982, which was absent in the earlier DSS87P core (see discussion in Van Ommen and Morgan, 1996), is clearly present in these data from the new DSS96P core.

The data from this DSS96P core show increases in $\mathrm{H}_{2} \mathrm{O}_{2}$ and $\mathrm{HCHO}$ over the modern period. This increase is not statistically significant in the case of $\mathrm{H}_{2} \mathrm{O}_{2}$, but the increase in $\mathrm{HCHO}$ is unambiguously significant $(>5 \sigma)$. Some of the change during the modern period is likely to be related to the effects of progressive burial in the upper layers. Processes of ventilation and diffusion plus changes in temperature, irradiance and porosity affect the final concentrations. We assume here that these effects are largely confined to the upper firn and do not make a significant contribution to the changes seen between the modern-c period (at depths of $14-19 \mathrm{~m}$ ) and the pre-industrial. Clearly, this assumption requires confirmation, which may come from future study of other shallow cores from different accumulation regions on Law Dome.

Examination of the $\mathrm{H}_{2} \mathrm{O}_{2}$ and $\mathrm{HCHO}$ concentrations over the modern period (Fig. 3) reveals some interesting features. Seasonality is clearly shown in the $\mathrm{H}_{2} \mathrm{O}_{2}$ concentrations. The HCHO concentrations are more erratic, but do show some suggestion of systematic behaviour in addition to the change in mean levels noted earlier. From the surface, concentrations rise markedly to a large peak in the previous autumn/winter layer. The correspondence may be fortuitous, but there is a suggestion of weaker peaks in the previous two autumn layers, and even possibly in the 1980 s series. The noisy nature of the HCHO concentrations is interesting in light of the very uniform peroxide cycles, which would suggest minimal snow redistribution and reasonably regular precipitation. It would seem that the processes responsible for largely removing seasonality in HCHO concentrations cannot simply be diffusional, or else these erratic fluctuations would also be smoothed away (occasional spikes up to several times mean concentrations are also seen in the sub-

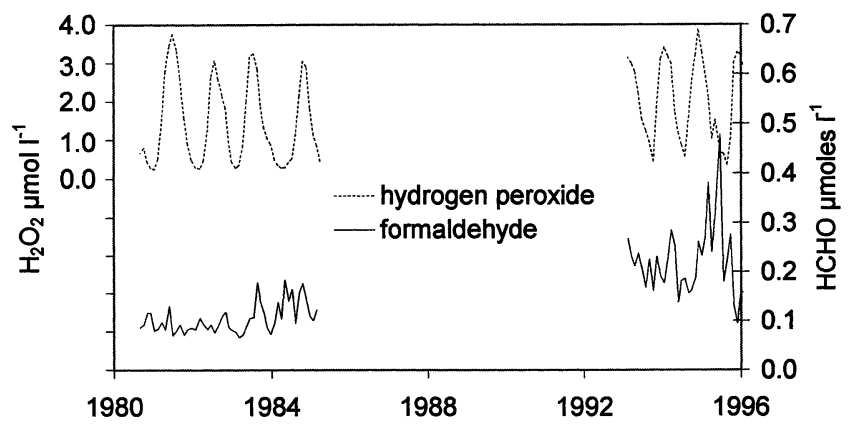

Fig. 3. Concentration of hydrogen peroxide (upper trace) and formaldehyde (lower trace), 1980-85 and 1993-96. annual resolution measurements for the pre-industrial period). Neftel and others (1995) discuss HCHO levels seen in pit studies in Greenland. They report a pattern where HCHO concentration shows a minimum at about $10 \mathrm{~cm}$ depth which they attribute to photolysis. A similar argument may explain the results seen here. The lower HCHO levels at the surface, it could be reasoned, are caused by photolytic destruction, at least at the snow-grain boundaries. The rise in concentration seen at around $0.6-1.0 \mathrm{~m}$ may then be attributed to uptake of $\mathrm{HCHO}$ from the atmosphere by forced ventilation, photolysis being no longer important at these depths. If so, the enhanced HCHO levels seen in autumn are the result of the competing effects of photolysis and ventilation and the depth scales over which they operate. If this argument is correct, the consequent pattern should be different at a site with different accumulation.

The changes seen in both species from modern to pre-industrial, early Holocene and LGM periods are all statistically significant if the additional $\mathrm{H}_{2} \mathrm{O}_{2}$ ("pre-industrial-a") measurement is used for the pre-industrial period. Most of the decrease in peroxide levels seen in the early Holocene and LGM periods is probably the result of destruction in ice and not of changes in atmospheric levels. Van Ommen and Morgan (1996) showed an overall loss of approximately $0.05 \mu \mathrm{mol} \mathrm{L}{ }^{-1}$ per 1000 years in the DSS peroxide record.

The elevated HCHO value in the early Holocene is not understood. Data from Summit (Greenland) ice cores (Fuhrer and others, 1993) show elevated HCHO in the last glacial (as is also seen here) but not during the early Holocene. HCHO measurements for Dye 3 and Byrd cores (Staffelbach and others, 1991) also show low levels in the early Holocene but which extend into the last glacial period without the higher levels seen in Summit or DSS data. Since, in this study, early Holocene results showed elevated HCHO concentrations, it was judged prudent to check the concentration in those cores. $\mathrm{HCHO}$ concentrations were measured again in samples freshly cut from the same DSS core and an adjacent DSS core. The results, given in Table 2, show concentrations very similar to the original ones even though more than 2 years elapsed between the two sets of measurements.

Previous studies in Antarctica have found $\mathrm{H}_{2} \mathrm{O}_{2}$ concentrations in ice cores of about $0.3-2.1 \mu \mathrm{mol} \mathrm{L}{ }^{-1}$ during the pre-industrial period (Neftel and others, 1995). The pre-industrial $\mathrm{H}_{2} \mathrm{O}_{2}$ concentration of $1-1.2 \mu \mathrm{mol} \mathrm{L}^{-1}$ measured in the present study places our results in the middle of the reported range. In contrast, $\mathrm{H}_{2} \mathrm{O}_{2}$ concentrations in Greenland ice cores are 1.2-5.9 $\mu \mathrm{mol} \mathrm{L}^{-1}$ (Neftel and others, 1995) which appears to be significantly higher than in Antarctica. This may be due to the differences in the modern $\mathrm{CH}_{4}$ : $\mathrm{CO}$ ratio between the Northern and Southern Hemispheres. Although $\mathrm{CH}_{4}$ concentration globally shows only a small interhemispheric difference, this is not the case for CO. Martinerie and others (1995) provide a convenient picture of a strong gradient in $\mathrm{CO}$ concentrations decreasing from the Northern to the Southern Hemisphere, with the modern $\mathrm{CH}_{4}$ : CO ratio at about 25 in Antarctica and 15 in Greenland. Since $\mathrm{H}_{2} \mathrm{O}_{2}$ is a product of $\mathrm{CO}$ oxidation by hydroxyl radical and $\mathrm{CH}_{3} \mathrm{OOH}$ from the analogous oxidation of $\mathrm{CH}_{4}$, it appears that the increased relative importance of $\mathrm{CO}$ compared with $\mathrm{CH}_{4}$ in the Northern Hemisphere may explain the higher $\mathrm{H}_{2} \mathrm{O}_{2}$ concentrations in Greenland ice cores, compared with those measured in Antarctica. 


\section{CONGLUSIONS}

Concentrations of total peroxides, speciated peroxides and formaldehyde were measured in a high-accumulation ice core from Law Dome, covering the modern, pre-industrial, early Holocene and LGM epochs. Two techniques were used to measure peroxides. In the first, total peroxide concentration was measured, and in the second, peroxides were measured individually by speciation on a HPLC column. No organic peroxides were detected using the HPLC technique, and total peroxide and hydrogen peroxide concentrations were in close agreement in all samples measured. From this we conclude that virtually all the peroxide in the ice was found to exist in the form of $\mathrm{H}_{2} \mathrm{O}_{2}$ at a level of $\sim 1.5 \mu \mathrm{mol} \mathrm{L}{ }^{-1}$ in modern ice. Based on analytical detection limits, the concentration of $\mathrm{CH}_{3} \mathrm{OOH}$ can be set at $<0.003 \mu \mathrm{mol} \mathrm{L}^{-1}$.

$\mathrm{H}_{2} \mathrm{O}_{2}$ concentrations were $1.6-2.1 \mu \mathrm{mol} \mathrm{L}^{-1}$ in modern ice with mean ages ranging from 1.5 to 12.5 years before 1996.0. In the pre-industrial period, $\mathrm{H}_{2} \mathrm{O}_{2}$ concentrations were significantly lower, with values of $1.0-1.2 \mu \mathrm{mol} \mathrm{L}^{-1}$ in ice having mean ages of 348 and 455 years before 1996.0. During the early Holocene, $\mathrm{H}_{2} \mathrm{O}_{2}$ concentrations were $0.6 \mu \mathrm{mol} \mathrm{L}^{-1}$ in ice with an average age of 6900 years before 1996.0; in the LGM, concentrations decreased to $0.2 \mu \mathrm{mol} \mathrm{L}{ }^{-1}$.

$\mathrm{HCHO}$ concentrations were measured in ice in the modern, pre-industrial, early Holocene and LGM epochs. During the modern period, concentrations were 0.22 $0.10 \mu \mathrm{mol} \mathrm{L}^{-1}$ for ice with mean ages of 1.5 and 12.5 years before 1996.0. Formaldehyde concentrations dropped to a mean of $0.07 \mu \mathrm{mol} \mathrm{L}^{-1}$ during the pre-industrial period, when ice had a mean age of 455 years before 1996.0. In the early Holocene, formaldehyde concentrations increased to $0.13 \mu \mathrm{mol} \mathrm{L}^{-1}$. Since previous studies have not measured such high concentrations in the early Holocene, measurements were repeated. More than 1 year after the original measurement, formaldehyde concentrations were determined in fresh cores cut from the same and an adjacent DSS core. The results of these analyses were very similar to the original measurements. The mean HCHO concentration measured in the LGM was $0.14 \mu \mathrm{mol} \mathrm{L}^{-1}$ and was more consistent with previous measurements.

\section{REFERENCES}

Barnola, J. M., D. Raynaud, Ye. S. Korotkevich and C. Lorius. 1987. Vostok ice core provides 160,000-year record of atmospheric $\mathrm{CO}_{2}$. Nature, 329(6138), 408-414.

Barnola, J. M., M. Anklin, J. Porcheron, D. Raynaud, J. Schwander and B. Stauffer. 1995. $\mathrm{CO}_{2}$ evolution during the last millennium as recorded by Antarctic and Greenland ice. Tellus, 47B(1-2), 264-272.

Chappellaz, J., J. M. Barnola, D. Raynaud, Ye. S. Korotkevich and C. Lorius. 1990. Ice-core record of atmospheric methane over the past 160,000 years. Nature, 345(6271), 127-131.
Davies, D. M. and M. E. Deary. 1992. A convenient preparation of aqueous methyl hydroperoxide and a comparison of its reactivity towards triacetylethylemediamine with that of other nucleophiles: the mechanism of peroxide bleach activation. 7. Chem. Soc. Perkin Trans., Part 2, 559-562.

Dong, S. and P. G. Dasgupta. 1987. Fast fluorometric flow injection analysis of formaldehyde in atmospheric water. Environ. Sci. Technol., 21, 581-588.

Etheridge, D. M., L. P. Steele, R. L. Langenfelds, R. J. Francey, J. M. Barnola and V. I. Morgan. 1996. Natural and anthropogenic changes in atmospheric $\mathrm{CO}_{2}$ over the last 1000 years from air in Antarctic ice and firn. $\mathcal{F}$. Geophys. Res., 101 (D2), 4115-4128.

Fuhrer, K., A. Neftel, M. Anklin and V. Maggi. 1993. Continuous measurement of hydrogen peroxide, formaldehyde, calcium and ammonium concentrations along the new Grip ice core from Summit, central Greenland. Atmos. Environ., Ser. A, 27(12), 1873-1880.

Heavner, D. L., M.W. Ogden and P. R. Nelson. 1992. Multisorbent thermal desorption/gas chromatograph/mass selective detection method for the determination of target volatile organic compounds in air. Environ. Sci. Technol., 26, 1737-1746.

Jacob, P. and D. Klockow. 1993. Measurements of hydrogen peroxide in Antarctic ambient air, snow and firn cores. Fresenius' 7. Anal. Chem., 346, 429-434.

Lazrus, A. L., G. L. Kok, S. N. Gitlin and J. A. Lind. 1985. Automated fluorometric method for hydrogen peroxide in atmospheric precipitation. Anal. Chem., 57, 917-922.

Lazrus, A. L., G. L. Kok, J. A. Lind, S. N. Gitlin, B. G. Heikes and R. E. Shetter. 1986. Automated fluorometric method for hydrogen peroxide in air. Anal. Chem., 58, 594-597.

Martinerie, P., G. P. Brasseur and C. Granier. 1995. The chemical composition of ancient atmospheres: a model study constrained by ice core data. 7. Geophys. Res., 100 (D7), 14,291-14,304.

Morgan, V. I., C. W. Wookey, LiJun, T. D. van Ommen, W. Skinner and M.F. Fitzpatrick. 1996. Site information and initial results from deep ice drilling on Law Dome, Antarctica. f. Glaciol., 43(143), 3-10.

Neftel, A., R. C. Bales and D. J. Jacob. 1995. $\mathrm{H}_{2} \mathrm{O}_{2}$ and HCHO in polar snow and their relation to atmospheric chemistry. In Delmas, R. J., ed. Ice core studies of global biogeochemical cycles. Berlin, etc., Springer-Verlag, 249-264. (NATO ASI Series 1: Global Environmental Change 30.)

Reiche, A. and R. Meister. 1933. Über Peroxyde des Formaldehyds: Pertioxymethylen und Tetraoxymethylen-Diperoxyd (X. Mitteil. über Alkylperoxide). Chem. Ber., 66, 718-727.

Reiche, A., and R. Meister. 1935. Über Peroxyde des Formaldehyds: Oxymethylhydroperoxide (XI. Mitteil. über Alkylperoxyde). Chem. Ber., 68, $1468-1472$.

Sigg, A. and A. Neftel. 1988. Seasonal variations in hydrogen peroxide in polar ice cores. Ann Glaciol., 10, 157-162.

Sigg, A. and A. Neftel. 1991. Evidence for a $50 \%$ increase in $\mathrm{H}_{2} \mathrm{O}_{2}$ over the past 200 years from a Greenland ice core. Nature, 351 (6327), 557-559.

Staffelbach, T., A. Neftel, B. Stauffer and D. Jacob. 1991. A record of the atmospheric methane sink from formaldehyde in polar ice cores. Nature, 349 (6310), 603-605.

Thompson, A. M. 1995. Photochemical modeling of chemical cycles: issues related to the interpretation of ice core data. In Delmas, R. J., ed. Ice core studies of global biogeochemical cycles. Berlin, etc., Springer-Verlag, 265-297. (NATO ASI Series 1: Global Environmental Change 30.)

Van Ommen, T. D. and V. Morgan. 1996. Peroxide concentrations in the Dome Summit South ice core, Law Dome, Antarctica. 7. Geophys. Res., 101 (D10), 15,147-15,152.

Van Ommen, T. D. and V. Morgan. 1997. Calibrating the ice core paleothermometer using seasonality. 7. Geophys. Res., 102(D8), 9531-9357.

Waddington, E. D., J. Cunningham and S. L. Harder. 1996. The effects of snow ventilation on chemical concentrations. In Wolff, E. W. and R. C. Bales, eds. Chemical exchange between the atmosphere and polar snow. Berlin, etc., Springer-Verlag, 403-451. (NATO ASI Series 1: Global Environmental Change 43. 